\title{
Dr Jekyll and Ms Hide
}

\section{Where are the women in science? And what would attract them from other sectors?}

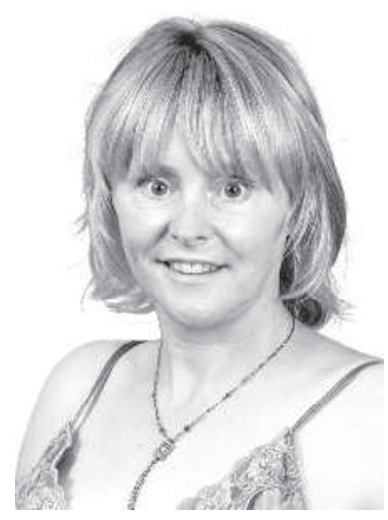

Jan Bogg

Women are under-represented in science, engineering and technology (SET) posts in most economies. In Britain, there is one woman for every five men in SET occupations. Some constants are global — for example, even fewer women work in engineering than in other scientific disciplines. There are also some striking differences by sector, with women being concentrated in health and education - key employment areas for women generally. Women account for less than a tenth of the SET workforce in manufacturing and construction.

In higher education, about a fifth of all researchers, senior lectures and professorial staff are female. Interestingly, reports published in 2005 by the Engineering and Physical Sciences Research Council and other UK research bodies show similar levels of grant success rates for women and men.

Worryingly, women are not earning equal pay. Data from the UK Office for National Statistics in 2005 indicate that women still earn less than men across SET sectors, such as science, health, teaching, research, business and public service.

As in other areas of employment, managerial occupations remain strongly gender-segregated. Women are concentrated in traditional areas such as health and social services.

On a more positive note, the number of women in

"Mentoring should be part of an employee's workload, not an add-on."
UK management roles has trebled during the past ten years, and women now account for $14 \%$ of company directors and $14 \%$ of managers in SET sectors.

This was the area in which my team did research with senior women in the bio- and health sciences during 2006. We interviewed 127 women in a variety of public and private-sector organizations.
They felt that, in order for others to progress, and in greater numbers, traditional models of management needed to be challenged throughout the organization. Equality and diversity training should be promoted.

How can employers achieve this? Employees require time investment, in terms of training and development to encourage and promote their growth. The training should address the employee's attitude and motivation. Also, there should be transparency in recruitment and promotion procedures. This must not just be in terms of policy - it must be known to be in practice throughout the organization.

The women we interviewed also named flexible working, work-life balance, networking and mentoring as important aspects for career progression.

Many employers now offer some form of flexible working, but consider your organization — is it more than a policy? Is it a reality? Do employees really feel that employers and colleagues endorse the policy? Employees may have outside commitments, so think about truly promoting flexible working wherever possible. Encourage some networking events within work hours, as some employees - men as well as women - have to care for children or elderly relatives. Working late may be difficult for them, making them feel they must let down either their colleagues or their dependants. Covering the cost of care by someone else could help.

When it comes to promotions, does your organization reward people for working long hours? Quality of work should be more important than hours spent in the workplace. Remember that allowing for a healthy work-life balance will provide benefits for the organization in terms of productivity, creativity and commitment. Do we really need a long-hours culture? If an experiment has to be completed, a product launched or a paper finished, there may be a rationale for working long hours. But this should be the exception, not the norm. Flexibility should work in more than one direction.

Encourage a mentoring culture, train the mentors to provide a high-quality service and recognize that enforced mentoring does not always work, either because of personality clashes or reluctance by the

"Does your organization
reward people for
working long hours?
Quality of work
should be considered
more important."

mentor or protégé. Importantly, provide the time for mentoring as part of an employee's existing workload, instead of as an add-on.

Mentors may be able to assist in guiding protégés into suitable networks. This would not only promote networking but also remove some of the mystique often associated with networks, especially specific ones such as those for women only.

Currently my work is focused on developing the lessons learned into frameworks for change in policy and practice. This includes new research evaluating mid-career women working in the bio- and healthsciences sectors. Issues to be addressed include barriers, drivers and progression to seniority. The challenge for employers is to listen to research evidence and to adapt to changing workforce needs.

Jan Bogg is director of the Breaking Barriers Project, University of Liverpool, UK. For more information on the project, to see executive summaries or to complete the online questionnaire, visit www.liverpool.ac.uk/ breakingbarriers 